\title{
An Analysis of Economic Burden of Hypertensive Patients Based on "System of Health Accounts 2011" and Multiple Layer Perceptron Neural Network
}

\section{Guojie Liu}

China Medical University

Xinyu Ji

China Medical University

Jingou Yang

shanxi university of chinese medicine

Yalan Zhu

China Medical University

Leying Wang

China Medical University

Xin Wang ( $\square$ wxinsmile@qq.com )

China Medical University https://orcid.org/0000-0001-7591-0103

\section{Research}

Keywords: Hypertension, Economic burden, Curative care expenditure, System of Health Accounts 2011, Multiple layer perceptron neural network

Posted Date: December 16th, 2020

DOl: https://doi.org/10.21203/rs.3.rs-127376/v1

License: (c) (i) This work is licensed under a Creative Commons Attribution 4.0 International License. Read Full License 


\section{Title page}

\section{Article title}

3 An analysis of economic burden of hypertensive patients based on "System of Health

4 Accounts 2011" and multiple layer perceptron neural network

5 Guojie Liu ${ }^{1}$, Xinyu $\mathrm{Ji}^{2}$, Jingou Yang ${ }^{3}$, Yalan $\mathrm{Zhu}^{4}$, Leying Wang ${ }^{5}$, Xin Wang ${ }^{4, *}$

6 1. School of Fundamental Sciences, China Medical University, Shenyang, Liaoning

7 Province, China.

8 2. The First Hospital of China Medical University, Shenyang, Liaoning Province, 9 China.

10 3. Humanity and Management College of Shanxi University of Chinese Medicine,

11 Shanxi Province, China.

12 4. College of the Humanities and Social Sciences, China Medical University, 13 Shenyang, Liaoning Province, China.

14 5. The First Clinical Department, China Medical University, Shenyang, Liaoning 15 Province, China

$16{ }^{*}$ Corresponding author: Xin Wang, Ph.D. College of the Humanities and Social

17 Sciences, China Medical University.

18 Mail address: No.77 Puhe Road, Shenbei New Area, Shenyang, Liaoning Province,

19 China (PRC), Zip code: 110122

20 Tel: + 86 18900911296, E-mail: wxinsmile@qq.com 


\section{Abstract}

2 Background: Hypertension requires long-term treatment and medication, which not

3 only affects people's health, but also brings heavy economic burden for families and

4 society. Therefore, it is meaningful to reveal the actual personal and socio-economic

5 burdens of hypertension based on a tool recognized internationally to improve management of hypertensive patients and provide more information for policy makers,

7 analysts, and international comparisons.

8 Methods: We collected expense records of 180441 hypertensive outpatients and

914763 inpatients in Shanxi Province of China in 2017. Curative care expenditure for 10 hypertension $\left(\mathrm{CCE}_{\mathrm{ht}}\right)$ were analyzed based on System of Health Accounts 2011, and 11 influencing factors were analyzed by multiple layer perceptron (MLP) neural network. 12 Results: In 2017, CCE $E_{h t}$ was US\$ 307.71 million, accounted for $3.63 \%$ of the total 13 CCE and $0.14 \%$ of GDP in Shanxi Province of China. CCE of hypertensive outpatients $\left(\mathrm{CCE}_{\mathrm{ht}-\mathrm{out}}\right)$ and inpatients $\left(\mathrm{CCE}_{\mathrm{ht}-\mathrm{in}}\right)$ accounted for $44.49 \%$ and $55.51 \%$ of the $\mathrm{CCE}_{\mathrm{ht}}$, drug fee accounted for $81.55 \%$ of $\mathrm{CCE}_{\mathrm{ht}-\mathrm{out}}$ and $22.50 \%$ of $\mathrm{CCE}_{\mathrm{ht}-\mathrm{in}}$, respectively. $\mathrm{CCE}_{\mathrm{ht}}$ increased from the age of 30, and the highest occured in age 6069. The patients with the age of 40-79 accounted for $86.49 \%$ of total $\mathrm{CCE}_{\mathrm{ht}}$. $\mathrm{CCE}_{\mathrm{ht}}$ of male patients were generally higher than that of female, and there is a significant difference between $\mathrm{CCE}_{\mathrm{ht}}$ for male and female in terms of age. The diagnosis and treatment capacity of primary health care system had been enhanced. New rural

21 cooperation medical insurance and urban employee basic medical insurance had the 22 trend of overusing, and burden of family healthcare expenditure was still very heavy.

23 In the MLP neural network, the top three influencing factors were drug fee, surgical 
1 fee and hospitalization days for inpatients, drug fee, examination fee and test fee for

2 outpatients.

3 Conclusions: To ease the economic burden of hypertensive patients and improve the

4 utilization efficiency of social resources, the policy makers should pay more attention

5 to the hypertensive patients aging 40-79, strengthen prevention and outpatient

6 treatment for young men and the inpatient treatment for women at older ages, further

7 increase support for primary health care system, standardize the treatment and

8 reimbursement of hypertension, and incline the reimbursement policy to outpatient

9 service.

\section{Keywords}

11 Hypertension, Economic burden, Curative care expenditure, System of Health

12 Accounts 2011, Multiple layer perceptron neural network 


\section{Background}

2 Along with the rapid development of society and economy, China has a high prevalence of

3 hypertension and it has risen from $18.8 \%$ in 2002 [1] to $29.6 \%$ in 2014 [2], ranking first in the

4 prevalence of major chronic diseases. Hypertension is a non-independent disease, which is

5 often accompanied by cardiovascular and cerebrovascular diseases. Hypertension requires

6 long-term treatment and medication, which not only affects people's health, but also bring

7 heavy economic burden for families and society [3]. Therefore, accurately estimating the

8 economic burden caused by hypertension is of great practical significance to develop an

9 intervention strategy and to achieve "global action plan for the prevention and control of

10 noncommunicable diseases 2013-2020" [4].

11 In our study, we collected expense records of 180441 hypertensive outpatients and

1214763 hypertensive inpatients from 1088 medical institutions in Shanxi Province in

13 2017, and calculated curative care expenditure(CCE) for hypertension(CCE $\left(\mathrm{E}_{\mathrm{ht}}\right)$ in the

14 frame of System of Health Accounts 2011(SHA2011) [5]. SHA 2011 is an

15 internationally recognized health policy analysis and evaluation tool for the

16 systematic description of the financial flows related to health care. According to the

17 situation of China, researchers from the China National Health Development

18 Research Center proposed a detailed system for the systematic description of the

19 financial flows in 2014 [6, 7]. In SHA 2011, CCE contains expenditure of curative

20 care, rehabilitative care and long-term health care, not include preventive care. Based

21 on the SHA 2011and combined with the actual situation of China's health system, the

22 CCE for hypertension in Shanxi Province can reveal the actual personal and socio-

23 economic burdens of hypertension.

24 Multiple layer perceptron(MLP) neural network is an important one of Artificial

25 Neural Networks, which can model complex functions and ignore irrelevant inputs 
1 and noise [8]. Due to the skewness and nonlinearity of medical expense data, we

2 select MLP neural network to analyze the influence factors of $\mathrm{CCE}_{\mathrm{ht}}$. All the

3 calculation and analysis will improve management of hypertensive patients and

4 provide more information for policy makers, analysts, and international comparisons.

\section{Methods}

6 Data sources

7 Data in different health institutions was collected from Shanxi Health Financial

8 Yearbook 2017, Shanxi Health Statistical Yearbook 2017, China National Health

9 Accounts Report 2017, Shanxi Health Accounts Report 2017, etc. Demographic data

10 was obtained from medical institutions, Shanxi statistical yearbook 2017, and public

11 health institutions.

12 Study samples

13 Multistage stratified cluster random sampling was applied in this study. First, we

14 chose four sample cities (Taiyuan, Changzhi, Yuncheng and Xizhou) from Shanxi

15 Province on the basis of the sufficient consideration of the level of health information

16 management system and economic development. Next, we chose one county and one

17 district in every city, and selected six township hospitals and community health

18 service organization in every country and district. At last, we chose medical

19 institutions and public health institutions on the basis of the type of institutions or

20 administration structure. The final valid sample included 180441 hypertensive

21 outpatients and 14763 inpatients from 1088 medical institutions. The basic

22 information of sample included gender, age, disease coded by International

23 Classification of Diseases Tenth Revision(ICD-10) and Global Burden of Disease 
1 (GBD), total expense, drug fee, examination fee, level of health institutions, financing

2 schemes, etc.

\section{Calculation of CCE in the frame of SHA 2011}

4 CCE consists of curative income and allowance, which come from statistical

5 yearbook and financial yearbook. All the calculations were performed by the software

6 STATA 12.0. $E_{\text {tincome }}$ is total income in different health institutions of Shanxi

7 Province, includes curative and partial preventive expenditure, can be queried from

82017 Shanxi Health Statistical Yearbook. $e_{i}, e_{p r e}$ and $e$ are curative income of per

9 patient, total preventive expenditure and total income in the sample. Through formula

10 (1), we can remove preventive expenditure and get curative income $E_{c \text {-income }}$ of

11 outpatient or inpatient in deferent health institutions of Shanxi Province. $E_{\text {income }}$

12 represents curative income in various dimensions, such as age, gender, region, etc.

$13 \frac{e_{i}}{e-e_{p r e}}$ is a sharing coefficient of per patient. Through formula (2), we can work out the

14 curative income of patient in various dimensions, such as gender, age, health

15 institutions and financing schemes.

$16 \quad E_{\text {c-income }}=E_{\text {t-income }}\left(1-\frac{e_{\text {pre }}}{e}\right)$

$17 \quad E_{\text {income }}=\sum_{k=1}^{n}\left(E_{\text {c-income }} \times \frac{e_{i}}{e-e_{\text {pre }}}\right)_{k}$

$18 E_{t-\text { subsidy }}$ represents total government subsidy in deferent health institutions of Shanxi

19 Province, including curative and partial preventive expenditure in outpatient and 20 inpatient, can be queried from 2017 Shanxi Health Financial Yearbook. $E_{p \text {-subsidy }}$ is

21 government subsidy in preventive service, collected from Yearbook as well. We can 
1 get curative government subsidy from formula (3). $N_{b \text {-subsidy }}$ is the number of hospital's

2 bed, $N_{o-s u b s i d y}$ is number of curative outpatient, and $\frac{N_{b-s u b s i d y}}{N_{b-s u b s i d y}-N_{o-s u b s i d y} \times 0.1}$ is a sharing

3 coefficient of inpatient. We can calculate government subsidy of inpatient $\left(E_{i \text {-subsidy }}\right)$

4 and outpatient ( $E_{o \text {-subsidy }}$ ) through formula (4) and (5) separately. Then times the

5 sharing coefficient of per patient, we can get the government subsidy of patient

6 ( $\left.E_{\text {subsidy }}\right)$ in various dimensions through formula (6). In formula (7), Curative care

7 expenditure $\left(E_{C C E}\right)$ is the sum of $E_{\text {income }}$ and $E_{\text {subsidy }}$ in various dimensions.

$8 \quad E_{c \text {-subsidy }}=E_{t-\text { subsidy }}-E_{p \text {-subsidy }}$

$9 \quad E_{i-\text {-subsidy }}=E_{c \text {-subsidy }} \times \frac{N_{b \text {-subsidy }}}{N_{b \text {-subsidy }}-N_{o \text {-subsidy }} \times 0.1}$

$10 \quad E_{o-s u b s i d y}=E_{c-\text { subsidy }} \times\left(1-\frac{N_{b-\text { subsidy }}}{N_{b \text {-subsidy }}-N_{o \text {-subsidy }} \times 0.1}\right)$

$11 \quad E_{\text {subsidy }}=\sum_{k=1}^{n}\left[E_{i-\text { subsidy }}\left(\text { or } E_{o \text {-subsidy }}\right) \times \frac{e_{i}}{e-e_{\text {pre }}}\right]_{k}$

$12 \quad E_{C C E}=E_{\text {income }}+E_{\text {subsidy }}$

\section{MLP neural network}

14 MLP neural network consists of an input layer, one or more multiple hidden layers

15 and an output layer. According to the principles of input layer variables, we choose

16 gender, age, surgical fee, drug fee, test fee, treatment fee, bed fee, consultation fee,

17 examination fee, nursing fee, diagnosis fee, hospitalization days, type of health

18 financing schemes, type of medical institutions and level of medical institutions as

19 input layer variables for inpatients. We choose gender, age, drug fee,

20 test fee, treatment fee, consultation fee, examination fee, registration fee, type of 
1 health financing schemes, type of medical institutions and level of medical institutions

2 as input layer variables for outpatients. We choose one hidden layer and curative

3 income from hypertensive patients as neuron in the output layer. The samples are

4 divided into training set and testing set randomly. According to the relative error, we

5 can get the cost model and variables importance rank. MLP neural network were

6 established by IBM SPSS Statistics 20.

\section{$7 \quad$ Results}

\section{Basic result of CCE for hypertensive patients}

9 As shown in table 1, in 2017, the CCE $\mathrm{Ch}_{\mathrm{ht}}$ was US\$ 307.71 million (RMB 2061.64

10 million yuan, average US\$1= RMB $¥ 6.7$, in 2017), accounted for $3.63 \%$ of the gross

11 CCE of Shanxi Province(CCE $\mathrm{Cs}_{\mathrm{sx}}$ ), and $0.14 \%$ of GDP. $\mathrm{CCE}_{\mathrm{ht}}$ accounted for $15.98 \%$ of

$12 \mathrm{CCE}$ for circulatory system diseases $\left(\mathrm{CCE}_{\mathrm{cd}}\right)$, which has the highest $\mathrm{CCE}$ in the ICD-

1310 disease classification. $\mathrm{CCE}_{\mathrm{ht}}$ accounted for $4.93 \%$ of CCE for non-communicable

14 diseases $\left(\mathrm{CCE}_{\mathrm{ncd}}\right)$ in the GBD disease classification. CCE of hypertensive outpatients

$15\left(\mathrm{CCE}_{\mathrm{ht}-\mathrm{out}}\right)$ and inpatients $\left(\mathrm{CCE}_{\mathrm{ht}-\mathrm{in}}\right)$ accounted for $44.49 \%$ and $55.51 \%$ of the $\mathrm{CCE}_{\mathrm{ht}}$,

16 drug fee accounted for $81.55 \%$ of $\mathrm{CCE}_{\mathrm{ht}-\text { out }}$ and $22.50 \%$ of $\mathrm{CCE}_{\mathrm{ht}-\mathrm{in}}$, respectively.

\section{Allocation of $\mathrm{CCE}_{\mathrm{ht}}$ in terms of age and gender}

19 The whole samples were divided into 10-year age groups: 0-9, 10-19, etc., 80-89 and

$2090+$. The allocation in Fig. 1 shows that $\mathrm{CCE}_{\mathrm{ht}}$ increased with age from the age of 30,

21 and the highest occured in the age group of 60-69. The patients aging from 40 to 79

22 accounted for $86.49 \%$ of total $\mathrm{CCE}_{\mathrm{ht}}$. Outpatient spending is 2.80 times of inpatient

23 spending in the groups under 50 years old, while the inpatient spending is 1.64 times

24 of inpatient spending in the groups over 50 years old. 
$1 \mathrm{CCE}_{\mathrm{ht}}$ of male patients was generally higher than that of women, accounted for $51.27 \%$

2 and $48.73 \%$ of $\mathrm{CCE}_{\mathrm{ht}}$, respectively. There is a significant difference between $\mathrm{CCE}_{\mathrm{ht}}$

3 for male and female in terms of age. As shown in Fig.2, the $\mathrm{CCE}_{\mathrm{ht}}$ for male

4 outpatients was significantly higher than that of female, especially in the group of 20-

549 , the $\mathrm{CCE}_{\mathrm{ht}}$ for male outpatients was about 1.76 times that of female. $\mathrm{CCE}_{\mathrm{ht}}$ for

6 female inpatients increased significantly from the age of 50, in the group of 50-89, the

$7 \quad \mathrm{CCE}_{\mathrm{ht}}$ for female inpatients was about 1.31 times that of male.

\section{$8 \quad$ Allocation of $\mathrm{CCE}_{\mathrm{ht}}$ in medical institutions and institution levels}

9 Medical institutions in this study included hospital (general hospital, traditional

10 Chinese medicine hospital and special hospital), basic medical institution and public

11 health institution. As data in Table 2 shows, $34.41 \%$ and $65.51 \%$ of outpatients chose 12 general hospital and basic medical institution, accounted for $76.56 \%$ and $23.43 \%$ of total $\mathrm{CCE}_{\mathrm{ht}-\mathrm{out}}$, respectively. $45.99 \%$ and $53.98 \%$ of inpatients chose general hospital and basic medical institution, accounted for $36.19 \%$ and $63.80 \%$ of total $\mathrm{CCE}_{\mathrm{ht}-\mathrm{in}}$, respectively.

Medical institution levels included provincial, municipal, district and county level. Data shows, $71.07 \%$ of outpatients and $74.75 \%$ of inpatients chose medical institution with county level, accounted for $45.33 \%$ of $\mathrm{CCE}_{\mathrm{ht}-\mathrm{out}}$ and $71.96 \%$ of $\mathrm{CCE}_{\mathrm{ht}-\mathrm{in}}$, respectively.

\section{Allocation of $\mathrm{CCE}_{\mathrm{ht}}$ in health financing schemes}

Financing schemes involve government subsidy, social medical insurance, voluntary medical insurance (commercial insurance, CI), other insurances (civil servant insurance, employment injury insurance, assistance, etc.) and family health care expenditure (out-of-pocket, OOP). Social medical insurance involves urban employee 
1 basic medical insurance (UEBMI), urban resident basic medical insurance (URBMI)

2 and new rural cooperation medical insurance (NRCMI). As data shows in Table 3,

$372.44 \%$ of outpatients and $88.78 \%$ of inpatients have social medical insurance, of

4 which $64.13 \%$ of outpatients and $71.48 \%$ of inpatients had NRCMI, respectively. The

5 patients with UEBMI of has the highest per capita reimbursement ratio. OOP

6 accounted for $47.85 \%$ of total $\mathrm{CCE}_{\mathrm{ht}-\text { out }}$ and $14.48 \%$ of total $\mathrm{CCE}_{\mathrm{ht}-\mathrm{in}}$, respectively.

7

\section{Analysis of influencing factors of $\mathrm{CCE}_{\mathrm{ht}}$ by MLP neural network}

9 In the MLP neural network, 9 and 8 hidden neurons are found out from hyperbolic 10 tangent function for inpatients and outpatients, respectively. Neural network structure

11 and result shows in Table 4. After continuous learning, testing relative error of MLP

12 model are $6.3 \%$ for inpatients and $3.1 \%$ for outpatients. The top three influencing

13 factors for inpatients are drug fee, surgical fee and hospitalization days. The top three

14 influencing factors for outpatients are drug fee, examination fee and test fee.

\section{Discussion}

17 In China, high prevalence of hypertension mainly concentrates in the northeast and

18 north China [9]. Shanxi Province is located in Northern China with a resident

19 population of 37 million [10] and the prevalence of hypertension was about $33.2 \%$ [11]

20 in 2014, that is, about 12.3 million residents of Shanxi Province suffer from

21 hypertension. Study shows $\mathrm{CCE}_{\mathrm{ht}}$ of Shanxi Province in 2017 accounted for $0.14 \%$ of

22 GDP [9]. Compared with $0.03 \%$ of GDP in the Latin American region in 2015[12],

23 hypertensive patients consumed a large number of health resources, which implies the

24 prevention and control system of hypertension should be strengthened. 
1 Study shows $\mathrm{CCE}_{\mathrm{ht}}$ increased with age, and the patients with the age of 40-79

2 accounted for majority of total $\mathrm{CCE}_{\mathrm{ht}}$. The aging population is an important factor that

3 increases the $\mathrm{CCE}_{\mathrm{ht}}$. As we know, China has entered the "aging society" [13], which

4 means that the economic burden caused by hypertension diseases will become heavier

5 and heavier.

6 Study shows that the $\mathrm{CCE}_{\mathrm{ht}}$ has increased significantly since the age of 30 in both

7 sexes. Consistent with literatures $[14,15]$, more and more young people suffer from

8 hypertension, and it has been a major public health problem in developing countries,

9 which is mainly attributable to unhealthy lifestyles of young people, such as

10 insufficient exercise, long-term use of smartphone and computers, lack of sleep, etc.

11 Once established, hypertension will systematically promote abnormal development 12 and progression of heart, blood vessel and kidney [16]. Therefore, in our study, the 13 outpatient spending accounted for majority of $\mathrm{CCE}_{\mathrm{ht}}$ before age 40 , while the 14 inpatient spending replaced it after age50.

15 Study shows the prevalence and economic burden of hypertension for male is 16 generally higher than that for female. Literature [17] shows that the prevalence of 17 hypertension was higher in men than women at younger ages, but higher in women 18 than men at older ages. This study also shows the economic burden of hypertension 19 for male outpatients were significantly higher than that of females in 20-49 age, which 20 is mainly caused by the fact that men of this age smoke, drink, have more work and

21 life stress [18,19], etc. While the economic burden of hypertension for female 22 inpatients increased significantly from age 50, and it likely due to dramatic changes in 23 estrogen level which can influence the vascular system [20,21]. Therefore, we should 24 pay more attention to the prevention and outpatient treatment for young men, and the 25 inpatient treatment for women at older ages. 
1 For a long time, Chinese patients tend to go to provincial and municipal general

2 hospitals rather than primary health care system, mainly due to insufficient medical

3 resources, imperfect medical system, limited level of general practitioner in primary

4 health care system, and patient distrust of community doctors [22]. Studies show that

5 basic medical institution is an effective way to control hypertension [23,24]. As a

6 result, the standardized prevention and treatment of hypertension has been included in

7 the national basic public health service program in 2009 [25]: patients with

8 hypertension can receive regular physical examination and standardized management

9 provided by basic medical institution free of charge, and basic medical institution

10 should give full play in the role of prevention and treatment of hypertension. In our

11 study, data shows (Table 2), $65.51 \%$ of outpatients and $53.98 \%$ of inpatients chose

12 basic medical institution, which effectively reduced $\mathrm{CCE}_{\mathrm{ht}}$, especially $\mathrm{CCE}_{\mathrm{ht}-\text { out }}$, which

13 only accounted for $23.43 \%$ of total $\mathrm{CCE}_{\mathrm{ht}-\mathrm{out}}$. Although $34.41 \%$ of outpatients and

$1445.99 \%$ of inpatients still chose general hospitals, more than $70 \%$ of hypertensive

15 patients chose medical institutions with county level. This suggests that the diagnosis

16 and treatment capacity of primary health care system has been enhanced. To better

17 prevent and control hypertension, the government should continue to increase support

18 for primary health care system, improve the standardization construction of primary

19 health care system, strengthen the training of community doctors, encourage the

20 exploration of a new mode of cooperation between primary health care system and

21 provincial(or municipal) hospital, guide more chronic patients to primary health care

22 system, reasonably divert patients with mild hypertension, effectively ease the

23 economic burden of families, and improve the utilization efficiency of social

24 resources.

25 Literature [26] shows that different types of medical insurance will have a great 
1 impact on patients' medical behavior and expenses. This study shows the majority of

2 hypertension outpatients and inpatients used social medical insurance. According to

3 the population characteristics report of Shanxi provincial government in 2017[10],

4 rural and urban population accounted for $42.66 \%$ and $57.34 \%$ of the total population,

5 respectively. However, in this study, the number of rural hypertension patients in

6 outpatient department was nearly 8 times that of urban patients, and the number of

7 hospitalized rural hypertension patients was 4 times that of urban patients. This shows

8 that NRCMI not only has been widely used in rural areas, but also has the trend of

9 overuse. Consistent with the literatures [27], in this study, UEBMI has the highest per

10 capita reimbursement ratio, which implies that patients with UEBMI are more likely

11 to over-pursue certain unnecessary high-tech materials, technologies, and high-cost

12 treatment programs. This suggests that the government should strengthen the

13 standardization of disease treatment, restrict unnecessary medical behavior, and ease

14 the burden of medical insurance. At the same time, the research also shows that the

15 government subsidy in the inpatient is 23 times that of the outpatient, and nearly half

16 of $\mathrm{CCE}_{\mathrm{ht}-\mathrm{out}}$ was paid by OOP, which indicates that burden of family health

17 expenditure is still very heavy in the outpatient treatment of hypertension. Therefore,

18 the government should incline the policy to outpatient service and increase the

19 reimbursement limit of outpatient expenses in basic medical insurance, which is

20 conducive to reducing the direct medical expenses of patients with hypertension.

21 Analysis of influencing Factors by MLP neural network shows that drug fee is the

22 most important influencing factor of $\mathrm{CCE}_{\mathrm{ht}}$. This is mainly due to long-term

23 medication, irrational use of medications by medical staff, blind and excessive

24 consumption of new special drugs and imported drugs, etc. In addition, in outpatient

25 treatment, the impact of examination fee and test fee on $\mathrm{CCE}_{\mathrm{ht}-\mathrm{out}}$ follows drug fee, 
1 which shows that the phenomenon of "relying on medicine, examination and test to

2 support doctors" still exists. Therefore, the government should further strengthen the

3 standardization and supervision of drugs and inspection items, improve the usage of

4 general medication and inspection efficiency. In inpatient, the impact of surgical fee

5 and hospitalization days on $\mathrm{CCE}_{\mathrm{ht}-\text { out }}$ follows drug fee. The high surgical fee is mainly

6 caused by the expensive imported medical materials. Research [28] shows some high-

7 value consumable medical equipments made by domestic manufacturers are fully

8 complies with international standards, and partially or completely replace imported

9 products. It is suggested that medical personnel use domestic supplies as much as

10 possible, which is feasible in terms of social and economic benefits. Hospitalization

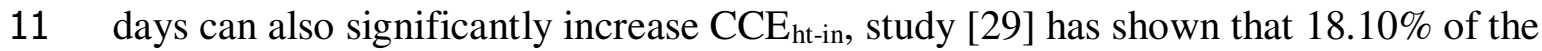

12 hospitalization days are actually unnecessary, which not only increases the economic

13 burden of patients, but also reduces the reasonable allocation of medical resources.

14 The hospital should shorten hospitalization time to reduce $\mathrm{CCE}_{\mathrm{ht}-\mathrm{in}}$ on the premise of

15 ensuring medical quality.

16 Our study has some limitations. First, this study samples reflect the economic burdens

17 of hypertension from medical institutions. As we all know, hypertensive patients need

18 long-term medication, and some patients may go directly to buy medicine in drugstore

19 instead of medical institutions. Therefore, the true financial expenditure of

20 hypertensive patients may be underestimated. Second, in the commercial insurance,

21 generally, the reimbursement of medical expenses is paid in advance by the patient,

22 and then reimbursed by the insurance company after treatment. So this study is biased

23 in allocation of $\mathrm{CCE}_{\mathrm{ht}}$ in commercial insurance.

\section{Conclusion}


1 From the calculation of curative care expenditure for hypertension in the frame of

2 SHA2011, we found: economic burden caused by hypertension diseases is still heavy,

3 NRCMI and UEBMI has the trend of overusing, and burden of family expenditure on

4 healthcare is still very heavy, and drug fee, check fee, test fee and hospitalization time

5 are important influencing factors of $\mathrm{CCE}_{\mathrm{ht}}$. Therefore, to ease the economic burden of

6 hypertensive patients and improve the utilization efficiency of social resources, the

7 policy makers should pay more attention to the hypertensive patients with 40-79 age,

8 strengthen prevention and outpatient treatment for young men and the inpatient

9 treatment for women at older ages, further increase support for primary health care

10 system, standardize the treatment and reimbursement of hypertension, and incline the

11 reimbursement policy to outpatient service.

\section{Abbreviations}

SHA2011: System of Health Account 2011; CCE: curative care expenditure;

14 MLP: multi-layer perceptron; ICD-10: International Classification of Diseases Tenth

15 Revision; GBD: Global Burden of Disease; $\mathrm{CCE}_{\mathrm{ht}}$ : curative care expenditure for

16 hypertension; $\mathrm{CCE}_{\mathrm{sx}}$ : gross $\mathrm{CCE}$ of Shanxi Province; $\mathrm{CCE}_{\mathrm{ht}-\mathrm{out}} \mathrm{CCE}$ of hypertensive

17 outpatients; $\mathrm{CCE}_{\mathrm{ht}-\mathrm{in}}$ : $\mathrm{CCE}$ of hypertensive inpatients; $\mathrm{CI}$ : commercial insurance; $\mathrm{OOP}$ :

18 family health expenditure; UEBMI: urban employee basic medical insurance; URBMI:

19 urban resident basic medical insurance; NRCMI: new rural cooperation medical

20 insurance; OECD: Organization for Economic Cooperation and Development; $\mathrm{CCE}_{\mathrm{cd}}$ :

$21 \mathrm{CCE}$ for circulatory system diseases; $\mathrm{CCE}_{\mathrm{ncd}}$ : $\mathrm{CCE}$ for non-communicable diseases. 


\section{Declarations}

\section{Ethics approval and consent to participate}

3 Not applicable

\section{Consent for publication}

$5 \quad$ Not applicable

\section{Availability of data and materials}

7 All data generated or analyzed during this study are included in this published article.

\section{Competing interests}

9 The authors declare that they have no competing interests.

\section{$10 \quad$ Funding}

11 The research was supported by the National Natural Science Foundation of China

12 (71673299) and Natural Science Foundation of Liaoning Province (20170541031).

\section{Authors' contributions}

14 GJL and XW designed the whole process and did the pre-research. GJL, XYJ, JOY, 15 and YLZ did the pre-research and statistical analysis. GJL was the main drafter of the 16 manuscript. YLZ and LYW contributed the coordination and manuscript editing. XW

17 was the director for the fund and designed ideas of research. All authors reviewed and 18 contributed to the subsequent drafts and approved the final version for publication. 
1 The authors express thanks to China National Health Development Research Center

2 for their help with SHA 2011 analysis. We also gratefully acknowledge the support of

3 Health Commission of Shanxi Province in providing data.

\section{References}

5 1. Wu Y, Huxley R, Li L, Anna V, Xie G, Yao C, et al. Prevalence, awareness,

6 treatment, and control of hypertension in China: data from the China National

$7 \quad$ Nutrition and Health Survey 2002. Circulation. 2008; 118(25):2679-86.

8 2. Wang JW, Zhang LX, Wang F, Liu LS, Wang HY. Prevalence, awareness,

9 treatment, and control of hypertension in China: results from a national survey. Am J

10 Hypertens. 2014; 27(11):1355-61.

11 3. Si Y, Zhou Z, Su M, et al. Catastrophic healthcare expenditure and its inequality for

12 households with hypertension: evidence from the rural areas of Shaanxi Province in

13 China. Int J Equity Health. 2017; 16(1):27.

14 4. World Health Organization. Updated revised draft global action plan for the

15 prevention and control of noncommunicable diseases 2013-2020.Geneva, 2013.

16 5. OECD, World Health Organization and Eurostat. A System of Health Accounts.

$17 \quad[\mathrm{M}]$. OECD publishing. 2011.

6. Zhai TM, Zhang YH, Wan Q, et al. Methodological Research on China Health

19 Expenditure Estimation Based On SHA 2011.Chinese Health Economics. 2015;

$20 \quad 34(3): 9-11$.

21 7. Chai PP, Zhang YH, Wan Q, et al. Estimation Results of China Curative Care

22 Expenditure Based on SHA 2011.Chinese Health Economics. 2015; 34(3):17-9. 
1 8. Zhao SY, Zhang XY, Li YL. Study on Diagnosic Model of Syndrome of

2 Deficiency of Both Yin and Yang in Hypertension Based on Decision Tree and

3 Neural Network. Chin. Arch. Tradit. Chin. Med. 2019; 37(5): 1120-3.

4 9. Li YC, Wang LM, Feng XQ, et al. Geographical variations in hypertension

5 prevalence, awareness, treatment and control in China: findings from a nationwide

6 and provincially representative survey. Journal of Hypertension. 2018; 36(1):178-87.

7 10.Shanxi Municipal Bureau Statistics. Shanxi statistical yearbook 2018. Available:

8 http://tjj.shanxi.gov.cn/tjsj/tjnj/nj2018/indexch.htm. Accessed: 10 Agu 2019.

9 11. Li YC, Feng XQ, Zhang M, Zhou MG, Wang N, Wang LM. Clustering of

10 cardiovascular behavioral risk factors and blood pressure among people diagnosed

11 with hypertension: a nationally representative survey in China. Scientific Reports.

$12 \quad 2016 ; 6: 27627$.

13 12. Stevens B, Verdian L, Pezzullo L, Tomlinson J, Zegenhagen S. The Economic

14 Burden of Hypertension in LatinAmerica. Value in Health, 2016, 19(7):A647-A648.

15 13. He JL, Yin Z, Duan WJ, et al. Factors of hospitalization expenditure of the

16 genitourinary system diseases in the aged based on "System of Health Account 2011"

17 and neural network model. Journal of Global Health. 2018; 8(2):34-6.

18 14. Perk J, De Backer G, Gohlke H, Graham I, Reiner Z, Verschuren M, et al.

19 European guidelines on cardiovascular disease prevention in clinical practice (version

20 2012). The Fifth Joint Task Force of the European Society of Cardiology and Other

21 Societies on Cardiovascular Disease Prevention in Clinical Practice (constituted by

22 representatives of nine societies and by invited experts). Eur Heart J. 2012;

23 33(13):1635-701. 
1 15. Nguyen QC, Tabor JW, Entzel PP, Lau Y, Suchindran C, Hussey JM, et al.

2 Discordance in national estimates of hypertension among young adults. Epidemiology.

$3 \quad 2011 ; 22(4): 532-41$.

4 16. Volpe M, Camm J, Coca A, Unger T. The cardiovascular continuum refined: a 5 hypothesis. Blood Press. 2010; 19(5):273-7.

6 17. Armas RN, Dobell E, Lacey B, Varona PP, Burrett JA, Lorenzo VE, et al. Burden

7 of hypertension and associated risks for cardiovascular mortality in Cuba: a

8 prospective cohort study. Lancet Public Health. 2019; 4(2):e107-e115.

9 18.Zhao L, Sun W, Wang JN, et al. Differences in the treatment and control of 10 hypertension in urban and rural residents of the northeastern region of the People's

11 Republic of China: a cross-sectional study. Clin exp hypertens. 2019; 41(4):366-72.

12 19.Yang L, Yan J, Tang XH, et al. Prevalence, Awareness, Treatment, Control and

13 Risk Factors Associated with Hypertension among Adults in Southern China, 2013.

14 Plos one. 2016; 11(1): e0146281.

15 20. Paolo DG, Paolo G, Cosimo AS, et al. Gender Differences in Epidemiology,

16 Pathophysiology, and Treatment of Hypertension. Curr Atheroscler Rep. 2018;

$17 \quad 20(3): 13$.

18 21. Mozaffarian D, Benjamin EJ, Go AS, et al. Heart disease and stroke statistics-

192015 update: A report from the American Heart Association. Circulation. 2015;

20 131(4): e29-e39.

21 22. Xiao R. Health Education Nursing of Community Hypertension. Chin Heal

22 Standard Management. 2016; 7(5):206-7. 
1 23. Zhang Q, Xu ZH, Zhou SS, Zhou K. Health management of community

2 hypertension based on regional medical association: an empirical study. Chin. Rem.

3 Clin.2018; 18(11):1888-90.

4 24. Chen XY, Li R. Application of chain management in education among

5 hypertensive patients of the community. Chinese Journal of Practical Nursing. 2017;

$6 \quad 33(2): 91-4$.

7 25. Liu LS. 2010 Chinese guidelines for the management of hypertension. Chinese

8 Journal of Cardiology. 2011; 39(7):579-616.

9 26.Zhang JY, Li XR, Gao H, Han Y. Influencing factors for hospitalization expenses

10 in patients with hypertension. Chin J Hyperten. 2020; 28(3): 271-5.

11 27. Bo L, Xie QJ. Analysis on the Hospitalization Expenses of Hypertension Patients.

12 Hosp Admin J Chin PLA. 2018; 25(9): 887-90.

13 28. Li Y, Du YQ, Guan ML, Wang JL, Li D, Zhang J. Factors analysis of

14 hospitalization costs of cardiovascular and cerebrovascular diseases in a tertiary

15 specialized hospital in Ningxia. Ningxia Medical Journal. 2016; 38:1264-6.

16 29. Hu Q, Luo ML. Analysis on factors influencing hospitalization length of hepatitis

17 B patients. Disease Surveillance. 2017; 32(8):674-7. 
1 Fig.1 Allocation of $\mathrm{CCE}_{\mathrm{ht}}$ of outpatient and inpatient in terms of age

2 Fig.2 Allocation of $\mathrm{CCE}_{\mathrm{ht}}$ in terms of age and gender 
Figures

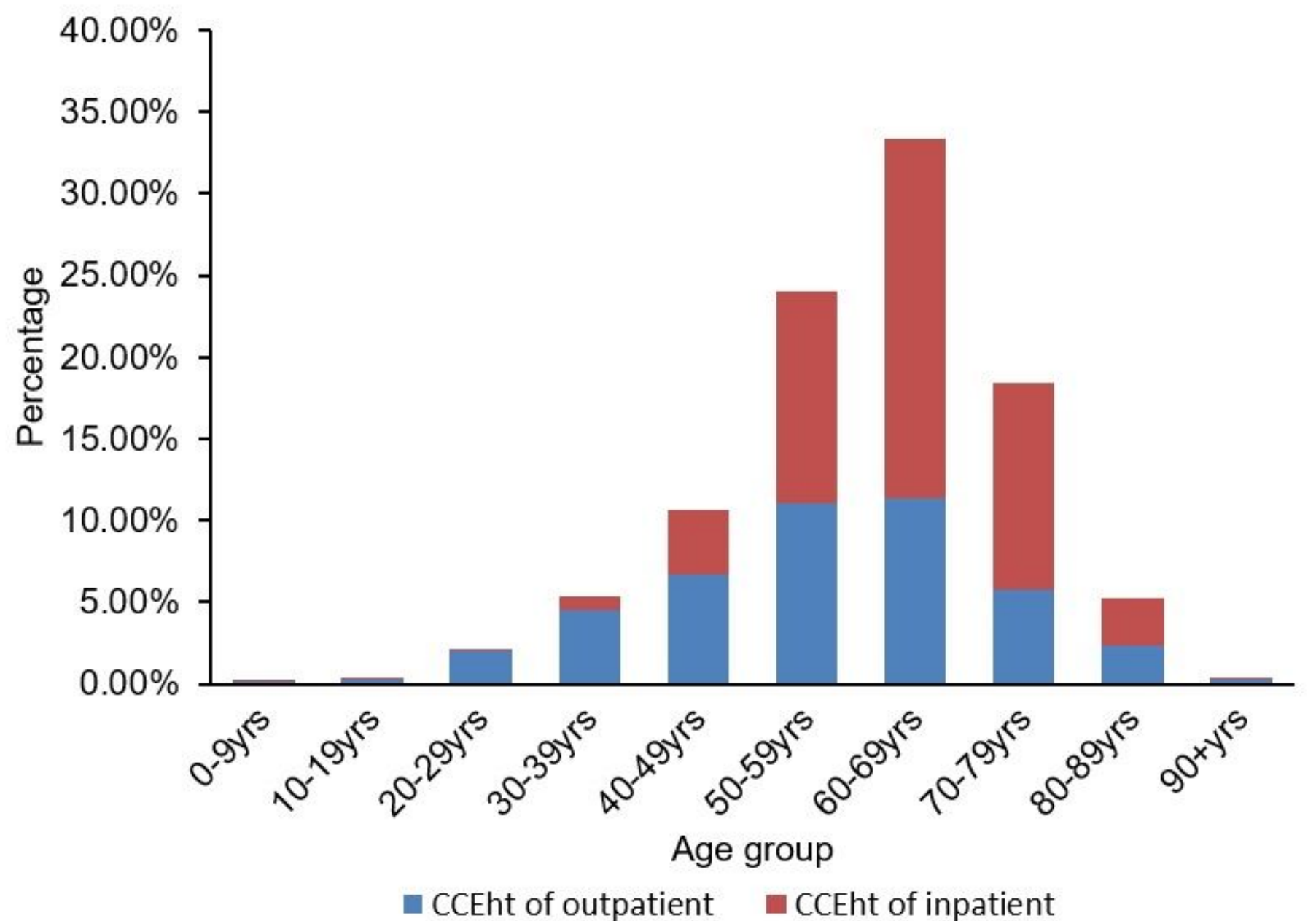

Figure 1

Allocation of CCEht of outpatient and inpatient in terms of age 


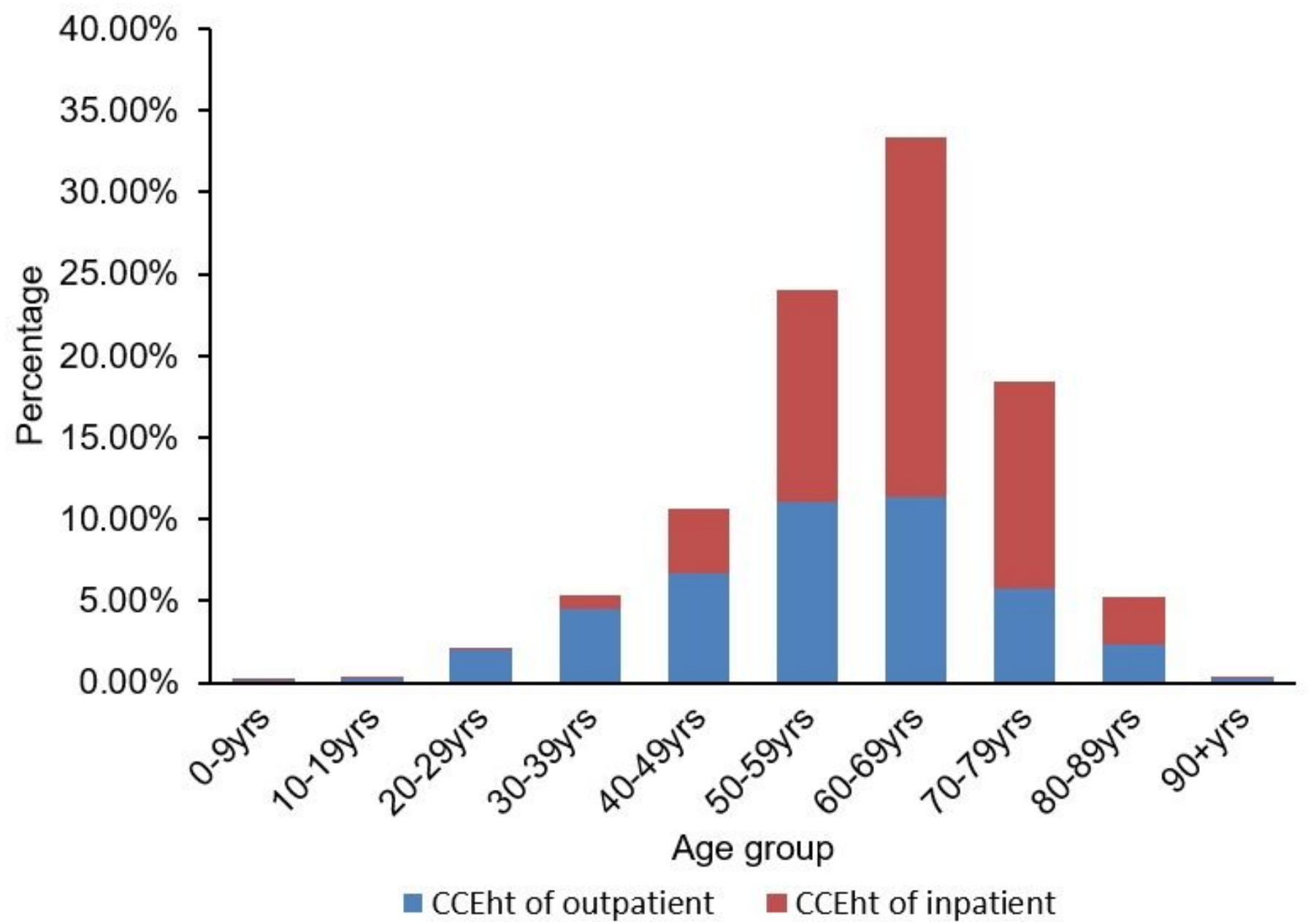

Figure 1

Allocation of CCEht of outpatient and inpatient in terms of age 


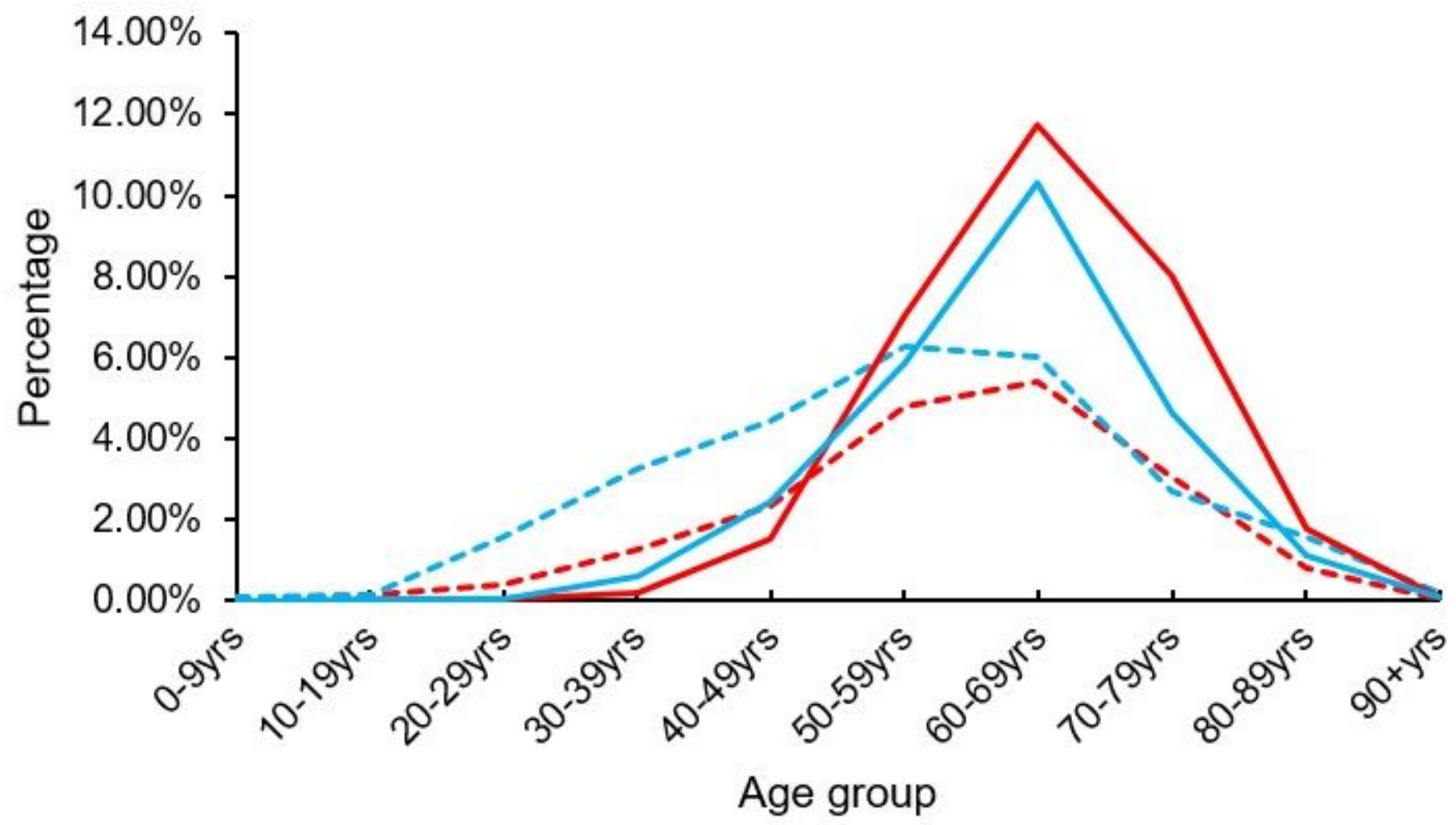

---- CCEht of female outpatients CCEht of female inpatients
-----CCEht of male outpatients CCEht of male inpatients

Figure 2

Allocation of CCEht in terms of age and gender 


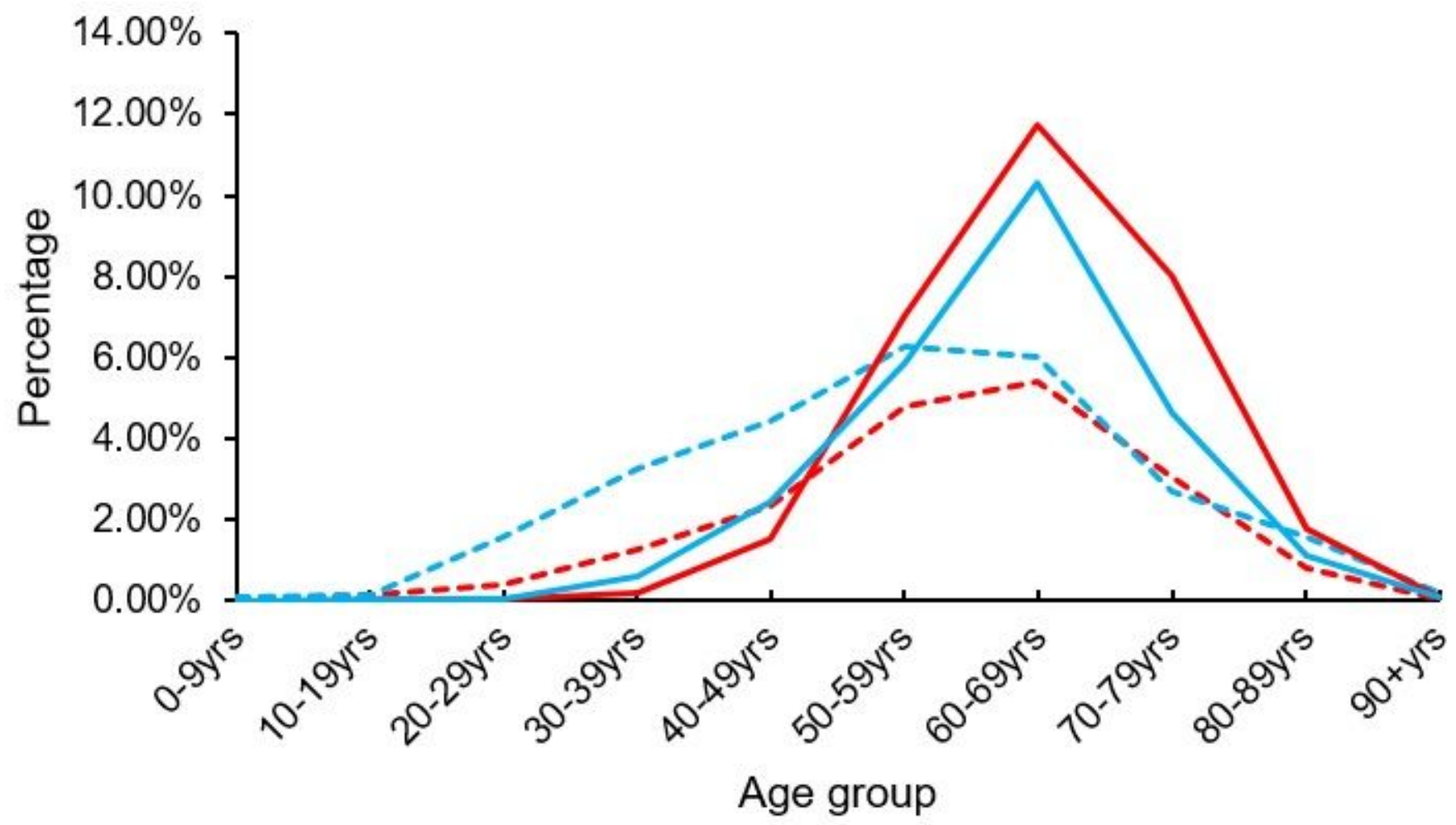

---- CCEht of female outpatients CCEht of female inpatients
----- CCEht of male outpatients CCEht of male inpatients

Figure 2

Allocation of CCEht in terms of age and gender

\section{Supplementary Files}

This is a list of supplementary files associated with this preprint. Click to download.

- Table1.docx

- Table1.docx

- Table2.docx

- Table2.docx

- Table3.docx

- Table3.docx

- Table4.docx

- Table4.docx 